\title{
Inteligência artificial e realidade aumentada em museus: estratégias projetuais para potencializar a mediação de conteúdo expográfico por meio do uso de tecnologias digitais da informação e comunicação (TDIC) em dois estudos de caso nacionais.
}

\author{
Artificial intelligence and augmented reality in museums: design strategies to \\ enhance the content mediation by the use of digital interactive communication \\ technology in two national case studies.
}

Me. Diego E. P. Ricca \& Dra. Clice de Toledo S. Mazzilli

tecnologia em museus; mediação; interação; Teoria da Atividade.

O presente artigo tem o objetivo de identificar diretrizes projetuais para fomento do processo de mediação de conteúdo por meio do uso de TDIC em museus, tendo como base uma análise de usuários em interação com dois estudos de caso presentes em museus brasileiros, a fim de propor estratégias projetuais capazes de fomentar o aprendizado do visitante em espaços culturais e expositivos. Com base na Teoria da Atividade somada a técnica de Videografia e entrevistas semi-estruturadas, realizou-se uma categorização dos pontos relevantes observados, produzindo um diagrama que sintetiza as estratégias projetuais elencadas em categorias de estímulos da interação voltadas a mediação de conteúdo, divididas em: aspectos espaciais; de problemas na usabilidade do sistema; elementos motivadores da interação e aspectos relacionais. Com base em tais categorias apresenta-se aqui uma leitura destas interações buscando refletir a respeito do efeito destas para a mediação de conteúdo nestes espaços.

\section{technology in museums; mediation; interaction; Theory of Activity.}

This paper aims to identify design guidelines to enhance the content mediation process through the use of digital ICT in museums, based upon an analysis of users interacting with two case studies present in Brazilian museums, in order to propose strategies designed to foster visitor learning in cultural and exhibition spaces. Based on the Activity Theory together with Videography technique and semi-structured interviews, a categorization of the relevant points was carried out, producing a diagram that synthesizes the projected strategies listed in categories of interaction stimuli focused on content mediation, divided into: spatial aspects; problems in the usability of the system; motivation elements of interaction and relational aspects. Based on these categories, we present here a reading of these interactions seeking to discuss on the effect of these for the content mediation on these spaces.

\section{Introdução}

Na realidade contemporânea é possível identificar que a digitalização de mídias e artefatos tem se tornado, de maneira crescente, um elemento importante da definição do nosso tempo atual. Tal mudança gera impactos políticos, sociais e econômicos e intensifica a necessidade de espaços culturais e museus se adaptarem a esta nova realidade, prática que se consolida cada vez mais no Brasil e no mundo. Discutir tais questões dentro do contexto brasileiro, e a partir do olhar da prática projetual do campo do design, mostra-se como uma discussão cada vez mais pertinente. Entende-se que, por meio de uma observação sensível da atividade de interação dos visitantes com dispositivos, é possível perceber como a disciplina do design pode contribuir para potencializar a mediação de conteúdo em museus com esteio o uso de tecnologias digitais da informação e comunicação (TDIC), nos aproximando de um maior entendimento da

Anais do 9 CIDI e 9 CONGIC

Luciane Maria Fadel, Carla Spinillo, Anderson Horta, Cristina Portugal (orgs.)

Sociedade Brasileira de Design da Informação - SBDI

Belo Horizonte | Brasil | 2019

ISBN 978-85-212-1728-2
Proceedings of the 9th CIDI and 9th CONGIC

Luciane Maria Fadel, Carla Spinillo, Anderson Horta,

Cristina Portugal (orgs.)

Sociedade Brasileira de Design da Informação - SBDI

Belo Horizonte | Brazil | 2019

ISBN 978-85-212-1728-2 
Ricca, D., \& Mazzilli, C. | Inteligência artificial e realidade aumentada em museus: estratégias projetuais para potencializar a mediação de conteúdo expográfico por meio do uso de tecnologias digitais da informação e comunicação (TDIC) em dois estudos de caso nacionais.

experiência humana no uso de dispositivos desta natureza.

Com base nisso, este artigo tem o objetivo de identificar aspectos projetuais para fomento do processo de mediação de conteúdo por meio do uso de TDIC em museus. Teve-se como base uma análise de usuários em interação com dois estudos de caso presentes em museus brasileiros, realizando uma coleta de dados fundamentada na experiência de interação com duas tipologias distintas de tecnologia - Realidade Aumentada (RA) e Inteligência Artificial (IA) - a fim de discutir diretrizes capazes de fomentar o aprendizado do visitante em espaços culturais e expositivos.

Selecionou-se, portanto, dois projetos: o primeiro - exemplar de uso de Realidade Aumentada (RA) - foi a instalação Relevos da Terra em 3D, situada no museu de ciências Catavento Cultural, em São Paulo. Esta faz parte do acervo permanente do museu, e utiliza da tecnologia da RA para demonstrar para os visitantes, por meio da interação com areia, os funcionamentos de relevos, rios e lagos. O segundo - já utilizando Inteligência Artificial (IA) foi o projeto temporário $A$ Voz da Arte, realizado na Pinacoteca do Estado de São Paulo, o qual é fruto de uma parceria entre o museu e a IBM, no sentido de experimentar a IA do Watson em um museu de arte, divulgando-a para o grande público.

Figura 1: instalação Relevos da Terra em 3D Fonte: < http://bit.ly/2O8RHV2> Acesso em jul/2019. e Figura 2: Visitante (PV1) interagindo com o projeto A Voz da Arte conversando a respeito da obra Bananal de Lasar Segall (1927). Fonte: Acervo do autor (2018).
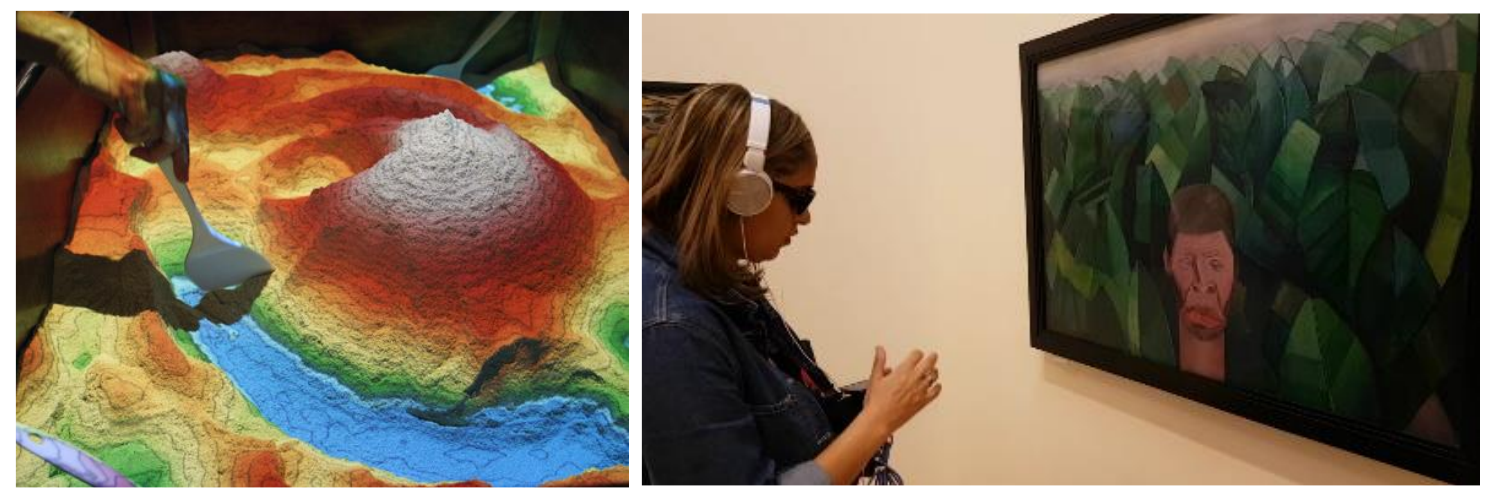

A coleta de dados em ambos os casos se deu com bases metodológicas fundamentadas na videografia, a qual baseia-se, segundo Meira (1994), em um método de coleta que admite a captura de múltiplas pistas visuais das atividades mediante filmagens em vídeo, permitindo que estes dados estejam menos sujeitos ao viés do observador do que anotações realizadas in loco. Esta foi seguida por entrevistas semiestruturadas com questões relativas a experiência individual dos participantes. A análise foi fundamentada na interpretação de manifestações verbais, gestuais e sociais - com bases no design centrado no usuário articulado à Teoria da Atividade.

\section{Referencial teórico}

Para interpretação dos dados teve-se embasamento em uma teoria capaz de dar um direcionamento na coleta e organização dos mesmos. Segundo Gay e Hembrooke (2004), pensar em direcionamento de projeto voltado as atividades desempenhadas é o foco do design centrado na atividade, cujo embasamento se dá na Teoria da Atividade (TA). Esta tem suas raízes na psicologia histórico-cultural, a partir dos pensadores russos das décadas de 1920 e 1930, cujas ideias em geral entendiam que a mente humana é fundamentada a partir da interação entre o ser humano e o mundo. Baseado nas teorias de Vygotsky e Leont'ev, a TA tem sua ênfase na construção de significado pela ação, a conexão entre o individual e o social, e o papel de ferramentas mediadoras para o desenvolvimento da experiência plena de atividade e aprendizado. Kari Kuutti descreve a TA como "uma estrutura filosófica e 
Ricca, D., \& Mazzilli, C. | Inteligência artificial e realidade aumentada em museus: estratégias projetuais para potencializar a mediação de conteúdo expográfico por meio do uso de tecnologias digitais da informação e comunicação (TDIC) em dois estudos de caso nacionais.

transdisciplinar de estudar diferentes formas de práticas humanas e processos de desenvolvimento, estando o indivíduo e o social interconectados ao mesmo tempo" (Kuutti, 1996, p.14). Esta teoria vê a atividade inserida em seu contexto social e ambiental, e considera esses elementos como relevantes no processo de leitura de uma ação humana, sendo usada no design para o processo de avaliação de uma interface ou dispositivo a partir de uma leitura detalhada das ações dos usuários.

Avaliar o uso de ferramentas e artefatos se estrutura a partir do conceito de Vygotsky (1984) de mediação, pelo qual esta teoria fundamenta o aprendizado humano. Nela se assume que o sujeito não interage diretamente com o ambiente, e utiliza de ferramentas e símbolos para mediar essa relação, os quais, assim como a linguagem, servem como ferramentas no desenvolvimento da mente e pensamento (Greenhow \& Belbas, 2007). A TA oferece uma série de conceitos para melhor descrição e entendimento da atividade, de forma a pensar não só em sistemas utilizáveis, como também, efetivamente úteis para o desenvolvimento de quem os usa (Kaptelinin \& Nardi, 2006).

\section{Resultados e análise}

As categorias de análise produzidas neste trabalho buscam organizar a mostra dos indicadores recolhidos por meio de padrões. Conforme dito acima, a TA se volta a ação humana inserida em seu contexto, e considera esses elementos como relevantes na leitura de aspectos subjetivos para avaliação de uma interface ou dispositivo. Por isso direciona-se o olhar para a atividade em si, observando como as ferramentas são utilizadas como mediação pelo usuário. Buscou-se, portanto, trabalhar focando em um reconhecimento das distintas atividades realizadas em cada caso, sendo primeiramente realizada a transcrição total das ações dos visitantes participantes da experiência, inspirada no uso das regras de transcrição do discurso oral de Preti et al. (1999). Com base nesse material transcrito, mapeamos as distintas atividades realizadas, de modo a encontrar não apenas as ações mais frequentes, como também as que ensejavam dados relevantes para compor os achados da pesquisa. Apresentamos resumidamente na sequência a organização destas informações distribuídas pelos dois estudos de caso.

No Catavento, o processo de coleta foi realizado em dois dias, somando um total de 3 h40min de vídeo e 41 grupos gravados, dos quais 12 estão aqui considerados. Estas foram integralmente transcritas, chegando-se a um total de 151 atividades consideradas, as quais foram divididas em 36 tipologias distintas. Já na Pinacoteca, 15 visitantes foram selecionados aleatoriamente durante quatro dias de coleta, tendo suas atividades registradas na interação com quatro obras do museu (figuras 3 a 6 ). Durante a transcrição e análise dos dados percebemos uma repetição constante de alguns gestos e interações, sendo estes pontos relevantes de serem destacados. As informações, após transcritas, foram resumidamente registradas, chegando ao cadastramento de 629 atividades consideradas, as quais foram listadas e divididas em 46 tipologias. 
Ricca, D., \& Mazzilli, C. | Inteligência artificial e realidade aumentada em museus: estratégias projetuais para potencializar a mediação de conteúdo expográfico por meio do uso de tecnologias digitais da informação e comunicação (TDIC) em dois estudos de caso nacionais.

Figuras 3, 4, 5 e 6: Fotos relativas as quatro obras analisadas. Respectivamente São Paulo (1924), de Tarsila do Amaral, Bananal de Lasar Segall (1927)., Lindonéia de Rubens Gerchman (1966) e O Porco de Nelson Leirner (1967). Fonte: Acervo Pinacoteca (2018).
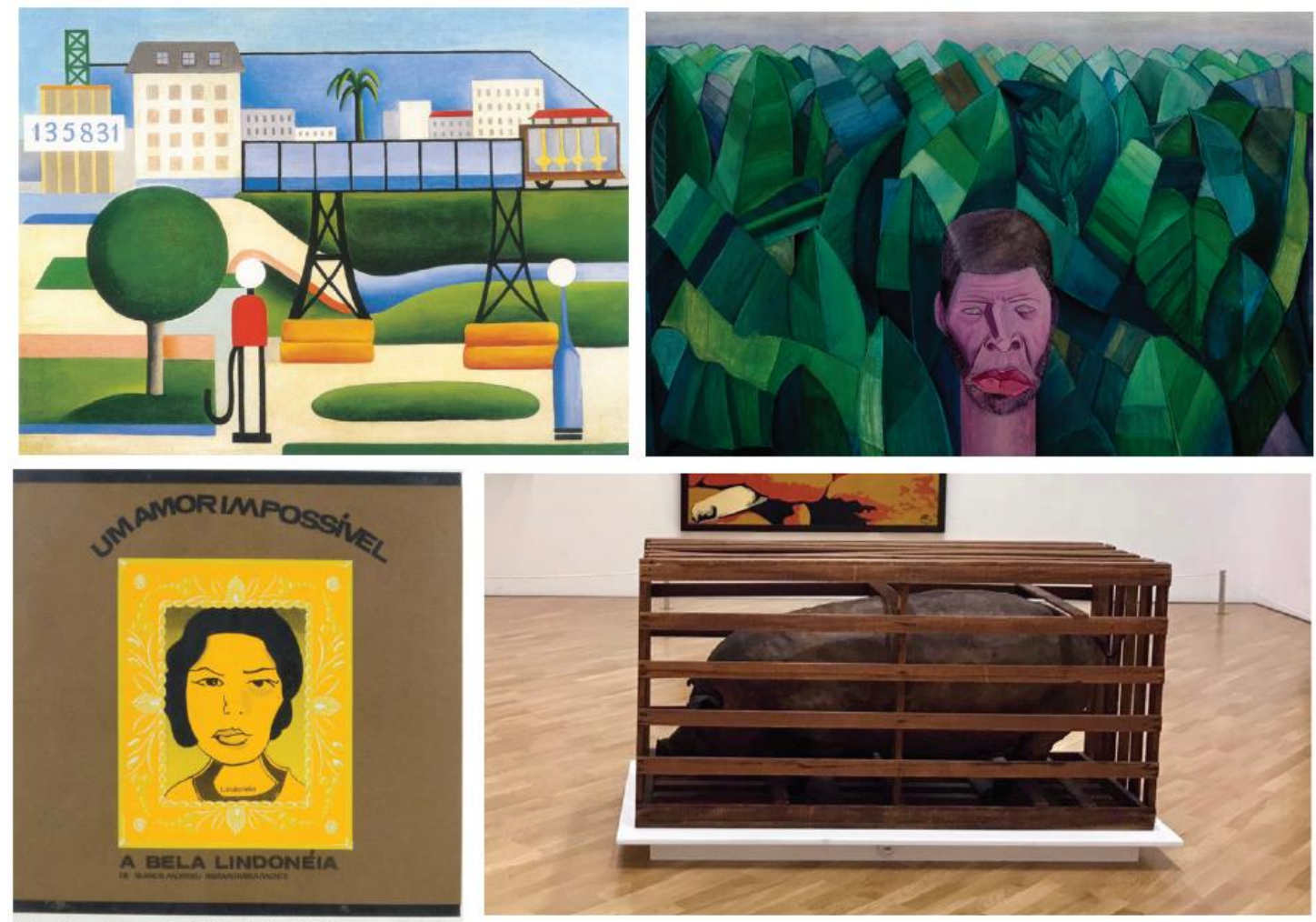

Com base nesta quantificação dos dados elaborou-se uma junção das atividades por meio de um quadro, apresentado na página a seguir, no qual é demonstrado graficamente as distintas atividades realizadas com suas respectivas quantidades expressas pela espessura da linha (Quadro 01). Tais dados foram então organizados por categoria a fim de identificar as naturezas qualitativas de cada atividade, e em quais aspectos estas podem ter influenciado a interação e a mediação da informação direcionada ao aprendizado do visitante. Com base nisso produziu-se o infográfico - realizado com base na aplicação online RAWGraphs ${ }^{1}$ representando a triagem de categorias realizadas, as quais foram divididas por cores em: aspectos espaciais; de problemas na usabilidade do sistema; elementos motivadores da interação e aspectos relacionais. Com esteio nestas realizou-se a leitura qualitativa dos dados, análise esta que foi condensada, para efeitos deste artigo, nos itens a seguir. Vale ressaltar que tais itens tratam de um resumo de todos os dados coletados e analisados dentro das páginas que este artigo se limita, sendo expostos exemplos pontuais a fim de ilustrar os pontos relevantes encontrados.

${ }^{1}$ RAWGraphs é uma aplicação web de código aberto para a criação de visualizações estáticas de dados que permitem livres modificações posteriores - <https://rawgraphs.io/> Acesso em: jul/2019. 
Ricca, D., \& Mazzilli, C. | Inteligência artificial e realidade aumentada em museus: estratégias projetuais para potencializar a mediação de conteúdo expográfico por meio do uso de tecnologias digitais da informação e comunicação (TDIC) em dois estudos de caso nacionais.

Quadro 01: Representação das atividades realizadas organizadas em categorias de análise. As linhas coloridas representam cada atividade cadastrada. Estas estão direcionadas às categorias que mais definem o teor da atividade. As espessuras de cada linha representam a quantidade de vezes que a atividade foi realizada.

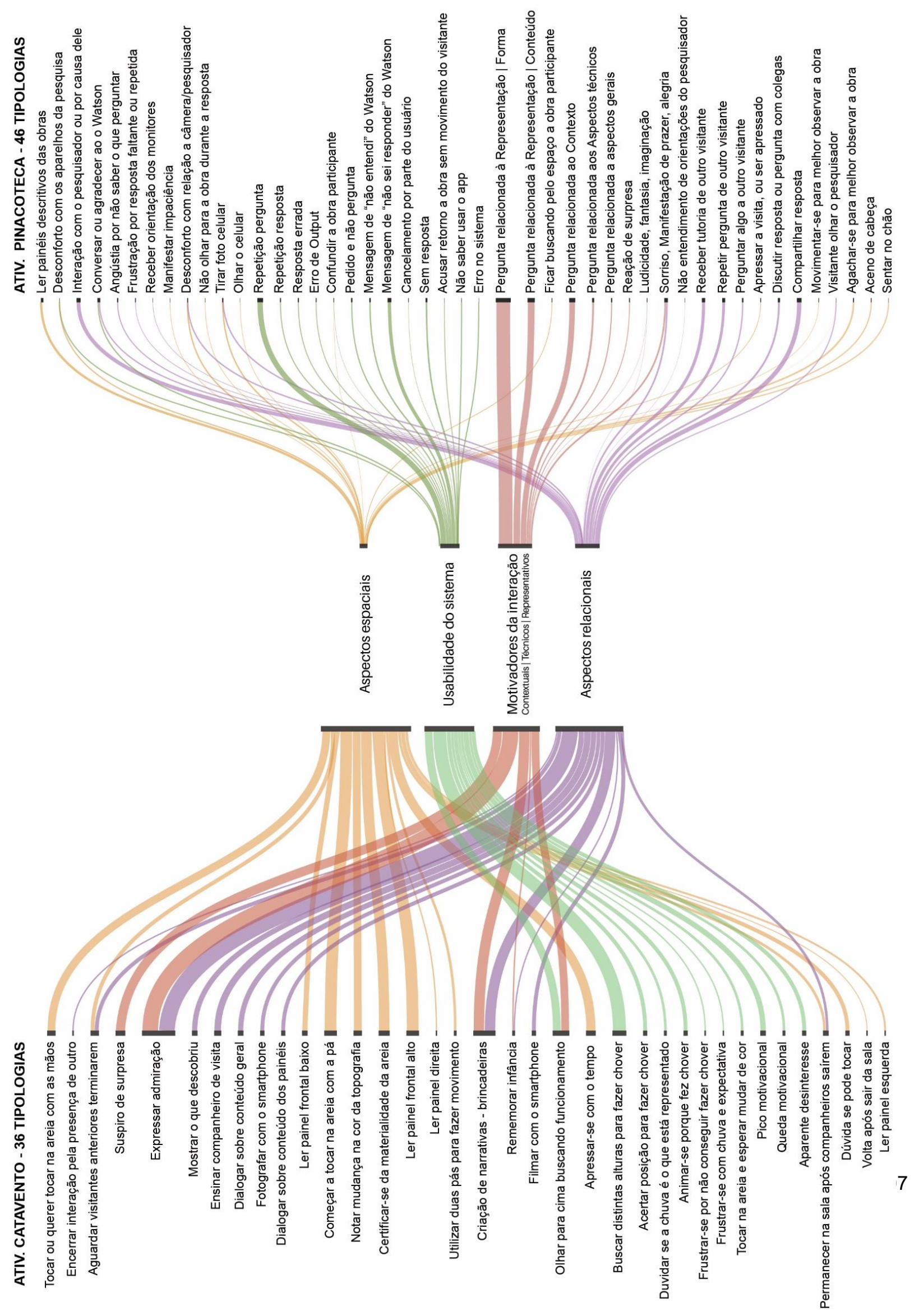


Ricca, D., \& Mazzilli, C. | Inteligência artificial e realidade aumentada em museus: estratégias projetuais para potencializar a mediação de conteúdo expográfico por meio do uso de tecnologias digitais da informação e comunicação (TDIC) em dois estudos de caso nacionais.

\section{Aspectos Espaciais}

As questões espaciais do conteúdo se concentraram nas informações explícitas dispostas pela interface, seja na disposição das obras no espaço do museu, como também na conformação dos painéis explicativos. Em ambos os casos, havia conteúdos explicitamente disponíveis para aqueles que quisessem em forma de painéis ou placas. No caso da Pinacoteca, estes se limitavam a descrições em placas adjacentes de nome, autor, data e material da obra. Neste caso as opiniões relativas ao meio de transmissão de conteúdo se voltaram ao aspecto da junção dos sentidos da audição e da visão, como relatado na entrevista com o Pinacoteca Visitante 01 (PV1): "você ver e você ouvir, aquilo vai ficar muito mais gravado. Porque não é só imagem. Isso tem uma função que é permitir que eu saia daqui e leve comigo uma lembrança maior do que eu simplesmente passar e ter lido."

Essa importância do aspecto dos sentidos se mostra, especialmente, na valorização da manifestação sonora da resposta do Watson, como também é justificado por PV2, ao afirmar que ouvir facilita o processo de registro da informação: "Porque muitas vezes, ou as pessoas não têm muita paciência pra ler o que tá escrito, ou não tem aquilo ali disponível." Neste depoimento é possível perceber como a relação com a ferramenta foi, para algumas visitas, algo relevante para a experiência no sentido de entender e internalizar o conteúdo apresentado. Como quando PV1 diz que o fato de ter som faz com que "(...) eu saia daqui e leve comigo uma lembrança maior do que eu simplesmente passar e ter lido. Uma voz me disse aquilo, e eu observei".

Já no Catavento, tais conteúdos eram bem mais extensos, dando oportunidade para que o visitante se aprofundasse nos assuntos relativos a linhas topográficas e deslizamentos. Dentre os conteúdos explícitos, são indicadas instruções básicas de como interagir com a instalação por meio de painéis nos quais são dispostos conteúdos mais aprofundados, a respeito das linhas topográficas e deslizamentos, por exemplo. Informações relativas a esta disposição do conteúdo foram também citadas em entrevistas, como no caso do depoimento do Catavento Visitante 03 (CV3), a qual exprime que o ato de mover a areia "[...] é um atrativo", mas a experiência não deve ser resumida a isso". Já sua esposa pontua que tal materialidade presente na areia e na cor são elementos que não fazem parte do propósito principal, e que tal apresentação ser realizada de modo tão chamativo leva a necessidade de tornar mais claro o conteúdo que, de fato, se deseja transmitir. Por tais opiniões podemos supor que a mediação do conteúdo por meio de um elemento chamativo e lúdico também acarreta desafios no sentido de tornar clara a informação que se deseja transmitir.

\section{Problemas na usabilidade do sistema}

Dentro disso cabe aprofundar nos próprios aspectos presentes na usabilidade do sistema, considerando os problemas e potencialidades encontrados na própria relação dos usuários com os dispositivos escolhidos. No caso da Pinacoteca, o uso do Watson, por ainda se tratar de um experimento único e de vanguarda, principalmente para o Brasil, ainda mostrou uma série de erros, principalmente voltados a dificuldade de entender as perguntas manifestadas. Por razão de se tratar de um sistema de IA que deve interpretar distintas modalidades de input, a necessidade repetição de pergunta foi uma das atividades mais realizadas, acontecendo 52 vezes. Isso provocou, em alguns casos, um nítido incômodo em alguns visitantes, como expresso no depoimento do filho de seis anos de PV4: "Mas eu fazia pergunta e ele nunca respondia! (...) eu perguntei se ele era olherudo [sic] ele num me respondeu, porque ele tinha um rabo, ele num respondeu". No diálogo, torna-se evidente o incômodo produzido pela falta de respostas, o que se confirmou pelo próprio PV4: "É...várias minhas ela não soube responder, tipo, uma pergunta básica: "a partir de quando o quadro de Tarsila foi escolhido?" Ou "porque motivo ele foi escolhido para participar?" aí ela diz: "não sei responder"...Isso é importante saber!"

No Catavento, diferente do Watson, tais questões de uso se deram muito mais pela existência de camadas de usabilidade subliminares na interação. Um exemplo que se destacou foi o oferecimento da possibilidade de fazer chover, o qual estava apenas disponível para 
Ricca, D., \& Mazzilli, C. | Inteligência artificial e realidade aumentada em museus: estratégias projetuais para potencializar a mediação de conteúdo expográfico por meio do uso de tecnologias digitais da informação e comunicação (TDIC) em dois estudos de caso nacionais.

aqueles que lessem uma placa acima do tanque, e colocassem a mão na altura correta estipulada pelos sensores. A existência deste "desafio" ensejou tanto impactos positivos como negativos na experiência de visitação. O impacto negativo tornou-se nítido, por exemplo, nas visitas de CV2 e CV9, as quais foram curtas - 01:42min e 01:32min, respectivamente - quando comparadas a média de aproximadamente 3 minutos por interação dos outros visitantes no espaço. Com suporte nestes dados, nas imagens e depoimentos destes visitantes, podemos supor que o maior motivo tenha sido que nestas interações a possibilidade de fazer chover tornou-se ponto-básico da experiência. Quando este não satisfez, elas saíram da sala, aparentemente em decorrência da frustração causada por não conseguir chegar ao objetivo almejado. Já um exemplo de impacto positivo se deu com CV1, de 11 anos, o qual estava expressando sinais de desinteresse em relação à interface, manifestando verbal e gestualmente o interesse em sair dali indo logo diretamente para outra brincadeira. Esse cenário, entretanto, muda, ao notar a possibilidade de fazer chover, ou seja, um aspecto, até então, novo na interface. Assim, é possível perceber como descobrir uma nova camada da experiência, até então escondida, pode provocar novas motivações nos visitantes.

Isso exprime algumas reflexões no que tange ao conceito de transparência trazido na TA, em que o artefato deve deixar nítido seu propósito. Deixar nítido não significa torná-lo óbvio, já que ressaltamos aqui, no exemplo de CV1, a importância do elemento surpresa para um maior engajamento dos usuários, sendo interessante manter aspectos específicos do sistema de modo subliminar. Donald Norman (2018), por sua vez, ressalta a importância de tornar os feedbacks visíveis na execução de uma ação, para que as pessoas possam saber os efeitos de suas interações. Segundo Csikszentmihalyi e Hemanson (1995) sem feedback, o envolvimento é pouco provável que se sustente.

\section{Elementos motivadores da interação}

Notou-se também uma série de aspectos dos sistemas analisados que provocavam reações de motivação da interação, ou seja, elementos estratégicos presentes no projeto que motivaram ações ou reflexões ligadas ao conteúdo proposto da visitação. Notou-se que tais estímulos se caracterizaram com relação a aspectos Contextuais, Técnicos e Representativos, segundo os distintos modos que estas se realizaram.

Os motivadores contextuais observados basearam-se em atividades de raciocínio do conteúdo que tratam da relação com o todo além do artefato, ou seja, manifestações que consideram o conteúdo transmitido em consonância com aspectos globais além do objeto em si, englobando o contexto no qual este está inserido. No caso da Pinacoteca, por exemplo, estas ocorreram, em especial, quando voltadas ao autor, período e fatos históricos das obras. Estas se apresentaram em forma de perguntas como: "Me conta um pouco da história dessa obra do Lasar Segall", de PV2 direcionada ao quadro Bananal; ou: "O seu criador...era um militante político?", de PV4, direcionada ao quadro Lindonéia. No Catavento, isso já se deu relacionado ao contexto geral que a instalação Relevos da Terra em $3 D$ se insere dentro da narrativa geral do museu. Como quando CV4 expressa: "(...) primeiro eles começam a falar do universo, etc. Depois vai trazendo pra assuntos mais da terra. Eu gostei de como começa de fora e vai trazendo pra dentro...os assuntos." Ou quando CV3 fala: "eu acho que essa experiência é uma consolidação de tooooda a narrativa anterior".

Nos exemplos citados é possível perceber um uso de raciocínio associativo, por meio de um conteúdo específico produzir reflexões em outros campos do conhecimento, como a relação com fatos históricos, ou com o universo e outros planetas. O desconhecimento de um dos elementos pode levar a suposições corretas de seu contexto, bem como pode guiar o visitante para que seus questionamentos sejam dedutivamente estruturados para melhor construção do conhecimento ali transmitido. A narrativa associada ao contexto do espaço museológico auxilia o visitante a ter uma ideia do todo, bem como, do papel daquele artefato para a experiência geral.

Os motivadores técnicos se deram por motivações de raciocínio ligadas aos aspectos tecnológicos do dispositivo. Expor suas partes constituintes é, em parte, positivo, pois pode 
Ricca, D., \& Mazzilli, C. | Inteligência artificial e realidade aumentada em museus: estratégias projetuais para potencializar a mediação de conteúdo expográfico por meio do uso de tecnologias digitais da informação e comunicação (TDIC) em dois estudos de caso nacionais.

estimular o interesse em conhecer mais do seu funcionamento. Por outro lado, pode ser um elemento que reduz a motivação do visitante, pois assim perde-se o aspecto do mistério. Como na interação de CV11, ao citar o que achou da experiência de interagir com a areia: "Eu achei meio estranho, pensei que era magia (...) mas, vi que tinha um projetor ali e um Kinect, aí deu pra dar uma sacada". Em sua interação foi possível perceber que a partir do momento em que ele entende que há um Kinect - e que é por conta dele que a projeção na areia muda de cor houve notório desestímulo de interesse. Isso se relaciona com o conceito de magia da ignorância, trazido por Ana Baltazar e Cabral Filho (2010), o qual se apresenta em tipos de participação em que o usuário só tem interesse no artefato até descobrir seu funcionamento; depois disso o interesse se desfaz.

As motivações também tiveram estreita ligação com questões representativas, que se caracterizaram por explicitar motivações direcionadas a aspectos de sentido, e intenções simbólicas do artefato; seja relacionado ao significado de cores e formas, bem como a questões mais subjetivas relativas ao conteúdo que intenciona ser ali transmitido. $\mathrm{Na}$ Pinacoteca tais manifestações se deram, tanto a partir de características materiais e físicas da obra, como a partir de perguntas relacionadas ao que estes elementos significam. Perguntas como: "A solidão foi a motivação para a obra?", direcionadas ao quadro Bananal; ou: "O que o artista expressou com essa obra?", direcionadas a escultura O Porco, são exemplos de questionamentos que tratam de aspectos simbólicos relevantes para entendimento e interpretação do artefato artístico ali exposto.

No museu Catavento as questões representativas observadas se deram muito em decorrência da relação da areia com a luz, em alguns casos com relação à materialidade da primeira. Na interação de CV10, por exemplo, foi possível perceber aspectos relevantes no sentido sensorial da representação das cores, na qual o visitante de 4 anos, após receber algumas informações da mãe quanto às cores quentes e frias associadas à representação das alturas dos declives, concatenou a materialidade da areia a outros elementos sensoriais, como maciez e dureza da cor projetada: "essa areia é um pouquinho dura, né mamãe? (referindo-se à areia projetada com cor relativa a montanha)...A água é macia né? e essa é quente (referindo-se a areia da montanha alta, de cor vermelha, que fizeram juntos)". Mesmo sendo interpretações, a rigor, equivocadas com relação a textura e temperatura da areia, o fato de haver um raciocínio associativo, para uma criança de sua idade, é exemplo relevante de transmissão de uma ideia da temperatura da cor por meio da interação proposta.

\section{Aspectos relacionais}

Nos dados coletados as relações sociais tiveram estreita ligação com aspectos emocionais, e foram bastante relevantes para a relação do visitante com o conteúdo que estava ali disposto. No Catavento, por exemplo, foi observado um especial teor lúdico presente na interação dos visitantes com seus pares. Neste ocorreram diversas criações de narrativas, muitas das quais se caracterizaram por tratar de narrativas direcionadas as formações de areia, criando histórias a partir disso. No caso de CV7 e CV8, por exemplo, a criação dos relevos com a areia ensejaram a imaginação dos mesmos ao criar situações sociais de compartilhamento de ideias. Notou-se também tal ludicidade ao observar adultos rememorando a infância, seja no formato de brincadeiras, como também na expressão de sentimentos saudosistas, como expressou CV6 ao tratar de como se sentiu na interação: "porque a gente passa por esse tempo do período de colegial, dos estudos iniciais da ciência (...) realmente deu em mim um sentimento de saudosismo. De reviver a época que isso nos foi ensinado, nos foi repassado".

$\mathrm{Na}$ Pinacoteca, um dos pontos relevantes observados é que a interação com o Watson se deu de modo prioritariamente individual. O aplicativo, em conjunto com o fone, constituiu um sistema de interação introspectivo, em que o output era dado para apenas uma pessoa. Observamos, entretanto, que muitos visitantes chegaram a ir de encontro a esta característica. Um exemplo disso se mostrou no sentido de tutoria, nos quais um dos visitantes assumia a função de ser um vetor da mediação do conteúdo ali disponível. Tal troca se realizava, em muitos casos, por meio da presença dos pais, ou visitantes mais velhos, que não participavam em conjunto da experiência. Como no caso de PV11, de nove anos, em que sua mãe - em 
Ricca, D., \& Mazzilli, C. | Inteligência artificial e realidade aumentada em museus: estratégias projetuais para potencializar a mediação de conteúdo expográfico por meio do uso de tecnologias digitais da informação e comunicação (TDIC) em dois estudos de caso nacionais.

oposição a oferecer perguntas prontas para a filha reproduzir - serviu de instrumento para que PV11 fizesse uma análise do que mais havia gostado, fazendo-a repetir, mostrando o que havia aprendido e internalizado com a experiência.

No Catavento tal aspecto de tutoria também se deu inúmeras vezes, como no caso de CV1, de onze anos, no qual sua irmã assumiu esta função de tutora do conteúdo, conforme ele relatou em entrevista: "Foi importante porque minha irmã me explicou bem mais o que que era, que eu não entendia o que que eu fazia. Aí ela falou: "coloca a mão assim...aí chove (..)". Isso também foi algo muito presente na interação de CV10, de quatro anos, em que sua mãe teve nos painéis uma base sólida para Ihe explicar diversos assuntos complexos que ele perguntava, trazendo falas como: "(...) quando mais você vai colocando areia mais vai ficando alto ó. Cores quentes, tá vendo? Vermelho é uma cor quente, ó, é como tá escrito ali ((apontando para o painel)). E se você cavar mais aqui, tá vendo que vai ficando mais azul, mais roxinho".

A maneira como o visitante vê e sente o espaço expositivo é diretamente influenciada pela sua interação social. As pessoas compartilham suas experiências com os outros - seja com conhecidos ou não - mediante ações verbais ou corporais (Vom Lehn, 2006). Uma ideia fundamental da Teoria da Atividade (TA) é que a mente tem sua natureza social. Agimos com, ou para, outras pessoas, sejam elas grupos, organizações, comunidades ou culturas. Vygotsky (1984) sustenta que a cultura e a sociedade não são fatores externos à mente que a influenciam, e sim são elementos diretamente envolvidos na produção da mente.

Mediante os dados previamente citados em ambos os artefatos dos dois museus, foi observado que, nos casos em que o participante se encontrava só, as reações eram contidas e tímidas, quando comparado com quando este se encontrava em dupla ou grupo, sendo estas mais expressivas quando realizadas de maneira coletiva. Ressalta-se, portanto, a importância de que, em futuras aplicações de mediações desta natureza, possa haver abertura para o uso do aspecto social como diretriz projetual, permitindo interações conjuntas entre dois ou mais usuários.

\section{Conclusão}

Entender os meios e motivações utilizados pelos visitantes para adquirir conhecimento pela interação, tanto por gestos, perguntas, comentários, como também pelas opiniões expressas nas entrevistas, exprime-se como método relevante no entendimento das capacidades do artefato de mediar conteúdo. A escolha da natureza múltipla dos artefatos estudados como estudos de caso se mostrou frutífera no sentido de ressaltar aspectos notórios quanto a uma reflexão sobre o papel do design no sentido de dar bases férteis para que a mediação aconteça. Fundamentando-se na frase de Paulo Freire: "Ensinar não é transferir conhecimento, mas criar possibilidades para sua produção ou construção" (2002, p. 21), pode-se entender o designer de artefatos interativos mediadores de conteúdo em museus como um educador, que tem em seu poder meios para tornar o aprendizado mais enriquecedor

A relação da expografia com os gestos e movimentos corporais dos participantes foi capaz de nos fazer entender como eles fisicamente exploraram o ambiente, e como eles se relacionaram com os dispositivos da interface. Na TA, Greenhow e Belbas (2007), exprimem que o aprendizado é oriundo de uma relação entre sujeito (aprendiz), um objeto (tarefa, atividade, conteúdo a ser aprendido) e um artefato mediador (uma ferramenta, um computador, leis). Tal questão nos situa na própria noção do uso de instrumentos para estimular esta relação dos seres humanos com o mundo, e no uso de artefatos como elementos utilizados para potencializar a relação com o espaço, com o desenvolvimento da mente, e com a construção de conhecimento. Inúmeros artefatos foram desenvolvidos para mediar nossa relação com o nosso entorno, e é possível inferir que novas e distintas modalidades de transmissão de conteúdo podem ser uma maneira de tornar o caminho entre conteúdo e visitante mais facilmente cruzável. 
Ricca, D., \& Mazzilli, C. | Inteligência artificial e realidade aumentada em museus: estratégias projetuais para potencializar a mediação de conteúdo expográfico por meio do uso de tecnologias digitais da informação e comunicação (TDIC) em dois estudos de caso nacionais.

No sentido das distintas modalidades observadas, na Pinacoteca, com no uso verbal com IA para a realização de perguntas, o visitante torna-se, em muitos momentos, um mero receptor de informações. Já na RA, como pôde ser visto na instalação do Catavento, por haver essa liberdade de criação de uma imagem, e de uma interação social, a interação apresentou mais elementos distintos de atividades e de reflexão a respeito do conteúdo. Entendeu-se, com isso, que a RA apresenta mais insumos para a transcendência do conteúdo a partir da própria elaboração cognitiva da atividade, com base nos casos e dados aqui realizados.

Ao pensar no posicionamento do projetista ao propor estratégias projetuais para fomento da mediação de conteúdo em museus, entende-se que dar insumos para atividades dentro das dimensões encontradas seja um meio de promover interfaces e espaços mais ricos para a experiência de aprendizado e visitação. Perceber as categorias citadas como interrelacionadas se coaduna com a estratégia de ensejar, por meio do design, atividades que consigam estimular dimensões materiais, racionais e emocionais da ação. Com base nisso, entendese, então, que dar insumos para atividades dentro de um equilíbrio destas três dimensões seja um meio de promover interfaces e espaços mais ricos para a experiência de visitação, promovendo um pico ótimo de experiencia. Este conceito aqui levantado se relaciona com as questões previamente suscitadas pois, considerar propostas de design que abram espaço para um equilíbrio entre estímulos é o caminho que se compreende, ao fim destas análises, como um meio frutífero de gerar boas bases para que a mediação de conteúdo aconteça.

\section{Agradecimento}

Esta pesquisa consiste em parte da dissertação de mestrado em Design da FAU USP do primeiro autor do artigo. Foi financiada pela Coordenação de Aperfeiçoamento de Pessoal de Nível Superior (CAPES). Agradecemos pelo apoio concedido.

\section{Referências}

Baltazar, A. P., \& Cabral Filho, J. d. S. (2010). Magia além da ignorância: virtualizando a caixa preta. In H. Roscoe, P. Moran, \& T. Mucelli (Eds.), FAD-Festival de Arte Digital (pp. 19-23). Belo Horizonte: Instituto Cidades Criativas.

Csikszentmihalyi, M., \& Hemanson, K. (1995). Intrinsic Motivation in Museums: Why Does One Want to Learn? In J. H. Falk \& L. D. Dierking (Eds.), Public institutions for personal learning (pp. 67-77) Washington, DC: American Association of Museums.Donald Norman (2018).

Freire, P. (2002). Pedagogia da autonomia: saberes necessários à prática docente (25 ed.). Sao Paulo.

Gay, G., \& Hembrooke, H. (2004). Activity-centered design. An Ecological Approach.

Greenhow, C., \& Belbas, B. (2007). Using activity-oriented design methods to study collaborative knowledge-building in e-learning courses within higher education. International Journal of Computer-Supported Collaborative Learning, 2(4), 363-391.

Kaptelinin, V., \& Nardi, B. A. (2006). Acting with technology: Activity theory and interaction design: MIT press.

Kuutti, K. (1996). Activity theory as a potential framework for human-computer interaction research. Context and consciousness: Activity theory and human-computer interaction, 17.

Meira, L. (1994). Analise microgenetica e videografia: ferramentas de pesquisa em psicologia cognitiva. Temas em psicologia, 2(3), 59-71.

Preti, D. o. e. a. (1999). Discurso oral culto, O (F. USP Ed. (2. Ed, Projetos Paralelos,V.2) ed. Vol. 2). Sao Paulo: Editora Humanitas.

Vygotsky, L. S. (1984). A formacao social da mente. In: Sao Paulo: MartinsFontes. 
Ricca, D., \& Mazzilli, C. | Inteligência artificial e realidade aumentada em museus: estratégias projetuais para potencializar a mediação de conteúdo expográfico por meio do uso de tecnologias digitais da informação e comunicação (TDIC) em dois estudos de caso nacionais.

Vom Lehn, D. (2006). Embodying experience: A video-based examination of visitors' conduct and interaction in museums. European Journal of Marketing, 40.

\section{Sobre o(a/s) autor(a/es)}

Diego Ricca, Mestre, FAU USP, Brasil <diegoricca@usp.br>

Clice Mazzilli, PhD, FAU USP, Brasil < clice@usp.br> 